\title{
VALIDATION OF THE BRAZILIAN VERSION OF MINI-TEST CASI-S
}

\author{
Alfredo Damasceno', Adriane M. Delicio', Daniel F.C. Mazo', João F.D. Zullo', \\ Patricia Scherer', Ronny T.Y. $\mathrm{Ng}^{1}$, Benito P. Damasceno²
}

\begin{abstract}
Objective:To determine CASI-S accuracy in the diagnosis of dementia. Method:The Cognitive Abilities Screening Instrument - Short Form (CASI-S) was applied in 43 Alzheimer's disease (AD) patients and 74 normal controls. AD diagnosis was based on DSM-IV, NINCDS-ADRDA, and CAMDEX. CASI-S includes: registration, temporal orientation, verbal fluency (4-legged animals in 30s), and recall (3 words). Its maximum score is 33 points. A copy of 2 pentagons was added. Results: ROC curve showed an accuracy of 0.87 , with standard error of 0.032 , and $95 \%$ confidence intervall between 0.795 and 0.925 . The cut-off score for cognitive deficit was 23 , with sensitivity of $76.7 \%$, specificity $86.5 \%$, positive likelihood ratio (LR) 5.68 , and negative LR 0.27 . The cut-off score for subjects 70 years or older was 20 , with sensitivity of $71.4 \%$ and specificity $97.1 \%$. Conclusion:CASI-S is a practical test, with high specificity, particularly in individuals above 70 years of age. The adding of the drawing test did not improve its accuracy.
\end{abstract}

KEY WORDS: CASI-S, dementia, Alzheimer's disease, education.

\section{Validação da versão brasileira do mini-teste CASI-S}

RESUMO - Objetivo: Determinar a acurácia do CASI-S no diagnóstico de demência. Método: O CASI-S (Cognitive Abilities Screening Instrument - Short Form) foi aplicado em 43 pacientes com doença de Alzheimer (DA) e 74 controles normais. O diagnóstico de DA baseou-se no DSM-IV, NINCDS-ADRDA e CAMDEX. O CASI-S inclui: registro, orientação temporal, fluência verbal (animais quadrúpedes em 30s), e evocação (3 palavras). $\mathrm{O}$ escore máximo é 33 pontos. Foi adicionado um teste de cópia de 2 pentágonos. Resultados.A curva ROC mostrou acurácia de 0,87, com erro padrão de 0,032, e intervalo de confiança de 95\% entre 0,795 e 0,925. O ponto de corte para déficit cognitivo foi 23 pontos, com sensibilidade de $76,7 \%$, especificidade de $86,5 \%$, valor preditivo (VP) positivo de 5,68, e VP negativo de 0,27 . Para sujeitos com 70 anos ou mais, o ponto de corte foi 20 , com sensibilidade de $71,4 \%$ e especificidade de $97,1 \%$. Conclusão: O CASI-S é um teste prático, com alta especificidade, particularmente em indivíduos com idade acima de 70 anos. 0 teste de cópia dos pentágonos não melhorou sua acurácia.

PALAVRAS-CHAVE: CASI-S, demência, doença de Alzheimer, educação.

Mental changes in normal and pathological aging, particularly in Alzheimer's disease (AD), are becoming a serious public health problem as the old population increases, and they should be detected as early as possible for the treatment to be successful. The diagnosis of AD is based, first and foremost, on the finding of cognitive and behavioral changes compatible with a dementia syndrome. In the mild stages of $A D$, when the complaints are scanty, the diagnosis of this syndrome is often attained only by gathering more cognitive changes by means of a neuropsychological test battery. Such a comprehensive battery of tests with a range of scores for separate cognitive domains can provide profiles of performance that may help distinguish different forms of dementia, as well as monitor disease progression and treatment effects. However, in clinical practice, as well as in epidemiological studies, it is not feasible to submit every patient with suspected dementia to a thorough, stressful, and expensive investigation. So, after the interview and neurological examination, we often begin with a cognitive screening test as the Mini-Mental State Examination', Blessed Orientation-Memory-Concentration test (BOMC)2 ; or, for transcultural epidemiological studies of dementia, The Cognitive Abilities Scre-

\footnotetext{
Unit of Neuropsychology and Neurolinguistics, Department of Neurology, Medical School, State University of Campinas (UNICAMP) Campinas SP Brazil: ${ }^{1}$ Medical student; ${ }^{2} \mathrm{MD}$, Associate Professor of Neurology: This research was supported by FAPESP (Fundação de Amparo à Pesquisa do Estado de São Paulo) grants 99/05287-7, 99/05288-3, 99/05289-0, 99/05290-8, and 99/05291-4.
}

Received 25 August 2004, received in final form 13 December 2004. Accepted 15 February 2005

Dr. Benito P. Damasceno - Department of Neurology, Medical School, UNICAMP / Box 6111 - 13083-970 Campinas SP - Brasil. E-mail: damascen@unicamp.br 
ening Instrument (CASI), or its shortened version (CASI-S), introduced by Teng et al. ${ }^{3,4}$.

CASI complete form (CASI-C) provides quantitative assessment (scoring from 0 to 100) of attention, concentration, orientation, short-term memory, longterm memory, language abilities, visual construction (copying two intersecting pentagons), list-generating fluency, abstraction, and judgment. Its short form (CASI-S) covers the ability to repeat (register) three words and to recall them after an interval during which tests of temporal orientation and verbal fluency are performed. Recently, CASI-C effectiveness in screening dementia has been improved by the use of an alternative scoring system (i.e., a weighted sum of the scores from the 9 cognitive domains) ${ }^{5}$. In this study, short-term memory (delayed recall of 3 words or 5 objects) and orientation appeared to be the two most relevant domains and their combined score was shown to be more effective than the total score in screening dementia.

CASI-S sensitivity and specificity are similar to those of the complete form ${ }^{3}$. In a comparison study of CASI-S with MMSE and BOMC, using The Clinical Dementia Rating Scale $(C D R)^{6}$ as an independent indicator of dementia, all three tests had comparably high inter-examiner and test-retest reliabilities, and comparably high associations with the CDR scores $^{4}$. CASI-S subtests of register, recall, and orientation, derived from MMSE and BOMC, are the most predictive items found in other test batteri$\mathrm{es}^{4,7}$. There fore, some authors ${ }^{8}$ question the contribution of the other MMSE subtests in a quick evaluation of dementia. Compared to MMSE, CASI-S has been considered as easier and quicker to administer, and more appropriate for illiterate people, which constitute $15 \%$ of patients who seek our university hospital.

The aim of this study was (1) to verify CASI-S power in the screening of dementia syndrome, by determining its sensitivity, specificity, positive and negative likelihood ratios, and cutoff points in a sample of the Brazilian population comprising patients with $A D$ and controls; and (2) to verify if the addition of MMSE drawing test (copy of two intersecting pentagons) can improve CASI-S accuracy, since praxic-constructive tests are considered as good predictors of cognitive deficit ${ }^{9}$.

\section{METHOD}

Subjects - This study included subjects aged 40 to 95 years, even illiterate ones, comprising patients with Alzheimer's disease attended at our university hospital and normal volunteers from the community, particular- ly spouses and consorts of the patients. Exclusion criteria for normal volunteers were history or evidence of neurological or psychiatric disease, head trauma with loss of consciousness exceeding $30 \mathrm{~min}$, alcoholism or chronic occupational exposure to neurotoxic substances, and current use of medication likely to affect cognitive functions. All subjects gave their informed consent to participate, in accordance with the rules of our Medical School Ethics Committee.

Procedures - All subjects underwent medical history, physical and neurological examination, and evaluation with The Cognitive Abilities Screening Instrument - Short Fo rm $(\mathrm{CASI}-\mathrm{S})^{3}$. Testing took place at morning times in a quiet room of the hospital's Neuropsychology Unit.

CASI-S comprises following subtests: registration [ repeating three words: shirt, brown, honesty (altemative ly: shoes, black, modesty; or socks, blue, charity); score 0 to 3]; temporal orientation with graded scoring according to the closeness of the response to the correct answer (to year: 0-4; to month and date: 0-5; to week-day: 0-1; and to the time of day, allowing 59 minutes error: 0-1); verbal fluency (category: four-legged animals, scoring the number of correct answers in 30 seconds, up to 10); and recall ( remembering three words): spontaneous recall of each correct word got score 3 ; recall after category cueing (e.g., "something to wear"), score 2; recall after provided three choices (e.g., "shoes, shirt, socks"), score 1 ; and if still incorrect answer, score 0 . CASI-S maximum score is 33 points. In our version of this test (which can be obtained from the corresponding author by e-mail request), the question "What season are we in?" was substituted for "What time is it?", because in Brazil there a re no marked differences between the seasons. A test of constructional praxis was added [copy of two intersecting pentagons (MMSE subtest) or, for illiterate subjects, reproduction of two pentagons bound by one of their sides using matches; score 1 if correctly copied].

Diagnosis of dementia was based on DSM-IV criteria $^{10}$, as well as on NINCDS-ADRDA ${ }^{11}$ for Alzheimer's disease, and CAMDEX (Cambridge Mental Disorders of the Elderly Examination $)^{12}$ to grade dementia and differentiate it from depression. Computed tomography (CT), magnetic resonance imaging (MRI), cerebral blood flow imaging (SPECT tomography using technetium-99m-HMPAO), electroencephalography, cerebrospinal fluid analysis, and relevant laboratory blood tests were done to discard other causes of dementia. Evaluation of control subjects consisted only of interview, physical-neurological examination, and cognitive testing. Diagnosis of probable AD was done by a senior neurologist (BPD), and the cognitive testing by the other authors, which as much as possible were blind to the diagnosis.

Statistical analysis were performed with SAS System for Windows, version 8.2 (SAS Institute Inc.) ${ }^{13}$. We used the Chi-Square test for gender proportion, and MannWhitney $\mathrm{U}$ test to compare both groups (demented and 
controls) as regards age, education, and performance on cognitive tests. One way ANOVA and post hoc analysis with Tukey test were used for comparison of multiple sample means. Pearson correlation coefficient, and regression analysis were applied where appropriate. Significance level was $5 \%$ (two-tailed). CASI-S overall diagnostic accuracy was calculated through receiver operating characteristics (ROC) analysis, which provides inform ation relevant to the full range of scores that should be taken into account in making a decision about a cutting point for discriminating the presence or absence of disease ${ }^{14}$.

\section{RESULTS}

CASI-S was applied in 172 normal volunteers (95 men, 77 women), whose age ranged from 40 to 88 years (mean $59 \pm 12$ years), and schooling from 0 to 20 years (median 4 years; mean $5 \pm 4$ years). Mean of $5( \pm 2)$ minutes was spent in the application of the test. In the analysis of the data, all controls were divided into four age groups: Group 1 (from 40 to 49 years), Group 2 (50 to 59 years), Group 3 (60 to 69 years), and Group 4 ( $\geq 70$ years). They were also classified into five schooling groups: (1) illiterate, (2) elementary school (from 1 to 4 years), (3) secondary school (5 to 8 years), (4) high school (9 to 11 years), and (5) university ( $\geq 12$ years) (Table 1 ).

In the whole group of 172 subjects there was a slight negative correlation between age and CASI$S$ scores (Spearman correlation coefficient; $r=$ $0.1813, p<0.05)$, which is explained by the higher educational level of Group 1 subjects as compared to Group $2(p=0.02)$, Group $3(p=0.0005)$ and G roup 4 ( $p=0.01$; Mann-Whitney U test). This correlation disappears when the statistical analysis excludes Group 1 and takes into account only the other three age groups (from 50 to 88 years), which have similar educational levels. On the other hand, when the four age groups are compared with each other by means of one way ANOVA, they show no difference in performance on CASI-S $[F(3,168)$ $=1.36, p=0.2559]$.

Educational level was highly correlated to CASI$S$ total scores in the whole group of 172 normal volunteers (Spearman correlation coefficient; $r=0.3016$, $p=0.00005)$. One way ANOVA and post hoc analysis with Tukey tests also revealed significant differences between the five schooling groups on CASI$S[F(4,167)=3.5265, p=0.008]$, on account of the illiterate in comparison to the other groups (second a ry: $p=0.003$; high school: $p=0.02$; and university group: $p=0.003$ ), but not in comparison to elementary school group $(p=0.06)$.

The effect of educational level on CASI-S subtests was seen only in the recall task $[F(4,167)=$ $5.5597, p=0.0003$ ], which may be explained by the poor performance of the illiterate in comparison to the other schooling groups (elementary: $p=0.008$; secondary: $p=0.0002$; high school: $p=0.01$; and university: $p=0.0001$ ). All groups showed similar performance on registration (only two of 172 subjects missed one of the three points of the test), orientation $[F(4,167)=0.4032, p=0.80]$ and verbal fluency $[F(4,167)=0.6344, p=0.63]$. Another significant difference was found between elementary school and university groups both on recall test $(p=0.01)$ and CASI-S total $(p=0.03)$. As re $g$ a rdsthe additional test of constructional praxis, ANOVA revealed significant interg roup differences $[F(4,167)$ $=3.4651, p=0.009]$, on account of the illiterate in comparison to the other schooling groups (secondary: $p=0.01$; high school: $p=0.003$; university: $p=0.004)$, but without significant diff e rence compared to elementary school group $(p=0.09)$.

Table 1. Age, educational level and CASI-S scores in 172 normal volunteers.

\begin{tabular}{|c|c|c|c|c|c|c|}
\hline & $\mathrm{N}$ & $\begin{array}{l}\text { Mean CASI-S } \\
\text { score }\end{array}$ & $\begin{array}{l}\text { Standard } \\
\text { deviation }\end{array}$ & Median & $\begin{array}{l}\text { Minimum score } \\
\text { score }\end{array}$ & $\begin{array}{l}\text { Maximum } \\
\text { score }\end{array}$ \\
\hline All controls & 172 & 28.71 & 3.51 & 29 & 19 & 33 \\
\hline \multicolumn{7}{|l|}{ Age (years) } \\
\hline Group 1 (40-49) & 38 & 29.31 & 3.44 & 29.5 & 20 & 33 \\
\hline Group 2 (50-59) & 49 & 29.18 & 3.17 & 29 & 19 & 33 \\
\hline Group 3 (60-69) & 50 & 28.16 & 3.61 & 28.5 & 19 & 33 \\
\hline Group $4(\geq 70)$ & 35 & 28.17 & 3.83 & 28 & 20 & 33 \\
\hline \multicolumn{7}{|l|}{ Education (years) } \\
\hline Illiterate & 10 & 26.10 & 3.90 & 26.5 & 19 & 33 \\
\hline Elementary (1-4) & 102 & 28.36 & 3.68 & 29 & 19 & 33 \\
\hline Secondary (5-8) & 30 & 29.70 & 2.75 & 30 & 24 & 33 \\
\hline High school (9-11) & 12 & 29.33 & 2.10 & 29 & 25 & 32 \\
\hline University $(\geq 12)$ & 18 & 30.33 & 2.82 & 31 & 22 & 33 \\
\hline
\end{tabular}


Table 2. Demographics of 43 patients with Alzheimer's disease and 74 con trol subjects.

\begin{tabular}{lccc}
\hline & $\begin{array}{c}\text { Controls } \\
(\mathrm{N}=74)\end{array}$ & $\begin{array}{c}\text { Alzheimer's disease } \\
(\mathrm{N}=43)\end{array}$ & $\mathrm{P}$ \\
\hline Men/women & $28 / 46$ & $16 / 27$ & 0.946 \\
Age (years) & $67 \pm 9$ & $70 \pm 10$ & 0.103 \\
Education (years) & $5 \pm 4$ & $7 \pm 5$ & 0.055 \\
Illiterate & 6 & 2 & 0.475 \\
\hline
\end{tabular}

Table 3. Scores on the cognitive subtests for dementia and control groups.

\begin{tabular}{lccc}
\hline Test parameters & $\begin{array}{c}\text { Dementia patients } \\
\text { Mean } \pm \text { SD (range) }\end{array}$ & $\begin{array}{c}\text { Control subjects } \\
\text { Mean } \pm \text { SD (range) }\end{array}$ & $\mathrm{p}$ \\
\hline Registration & $2.58 \pm 0.95(0-3)$ & $3 \pm 0(3-3)$ & 0.0001 \\
Time orientation & $6 \pm 4(0-11)$ & $10 \pm 1(6-11)$ & $<0.0001$ \\
Verbal fluency & $4 \pm 3(0-10)$ & $8 \pm 2(1-10)$ & $<0.0001$ \\
Recall & $3 \pm 3(0-9)$ & $7 \pm 2(1-9)$ & $<0.0001$ \\
CASI-S total & $16 \pm 10(0-33)$ & $28 \pm 4(19-33)$ & $<0.0001$ \\
CASI-S total + praxis & $16 \pm 10(0-34)$ & $29 \pm 4(19-34)$ & $<0.0001$ \\
\hline
\end{tabular}

Table 4. Sensitivity, specificity, and likelihood ratios (LR) according to the differ ent cut-off points of CASI-S.

\begin{tabular}{lcccc}
\hline Cut-off & Sensitivity & Specificity & Positive LR & Negative LR \\
\hline$\leq 15$ & 46.5 & 100 & - & 0.53 \\
$\leq 16$ & 51.2 & 100 & - & 0.49 \\
$\leq 17$ & 53.5 & 100 & - & 0.47 \\
$\leq 18$ & 58.1 & 100 & - & 0.42 \\
$\leq 19$ & 65.1 & 95.9 & 16.06 & 0.36 \\
$\leq 20$ & 69.8 & 93.2 & 10.33 & 0.32 \\
$\leq 21$ & 72.1 & 89.2 & 6.67 & 0.31 \\
$\leq 22$ & 74.4 & 86.5 & 5.51 & 0.30 \\
$\leq 23$ & 76.7 & 86.5 & 5.68 & 0.27 \\
$\leq 24$ & 76.7 & 82.4 & 4.37 & 0.28 \\
$\leq 25$ & 76.7 & 75.7 & 3.16 & 0.31 \\
$\leq 26$ & 76.7 & 73.0 & 2.84 & 0.32 \\
$\leq 27$ & 81.4 & 64.9 & 2.32 & 0.29 \\
$\leq 28$ & 88.4 & 54.1 & 1.92 & 0.22 \\
$\leq 29$ & 95.3 & 41.9 & 1.64 & 0.11 \\
$\leq 30$ & 95.3 & 37.8 & 1.53 & 0.12 \\
$\leq 31$ & 97.7 & 20.3 & 1.23 & 0.11 \\
$\leq 32$ & 97.7 & 8.1 & 1.06 & 0.29 \\
\hline
\end{tabular}

We also studied 43 patients with AD and 74 controls (chosen randomly among the 172 normal volunteers), which were matched with the patients for age (with variation of 5 years) and education (with variation of 2 years) (see Table 2 for demographics). Both groups had similar gender proportion (ChiSqua retest) and mean age (Mann-Whitney $U$ test). Educational level was slightly higher in the demen- tia group, but not statistically significant $(p=0.055$; Mann-Whitney $U$ test). Ten controls and two patients with dementia were illiterate $\left(\chi^{2}=2.32, \mathrm{df}=1, \mathrm{p}\right.$ $=0.127)$. Dementia patients had lower scores on all cognitive subtests, as determined by Mann-Whitney $\mathrm{U}$ test (Table 3 ).

The dementia was mild in 26 , moderate in 7 , and severe in 10 patients. As regards their CASI-S total 


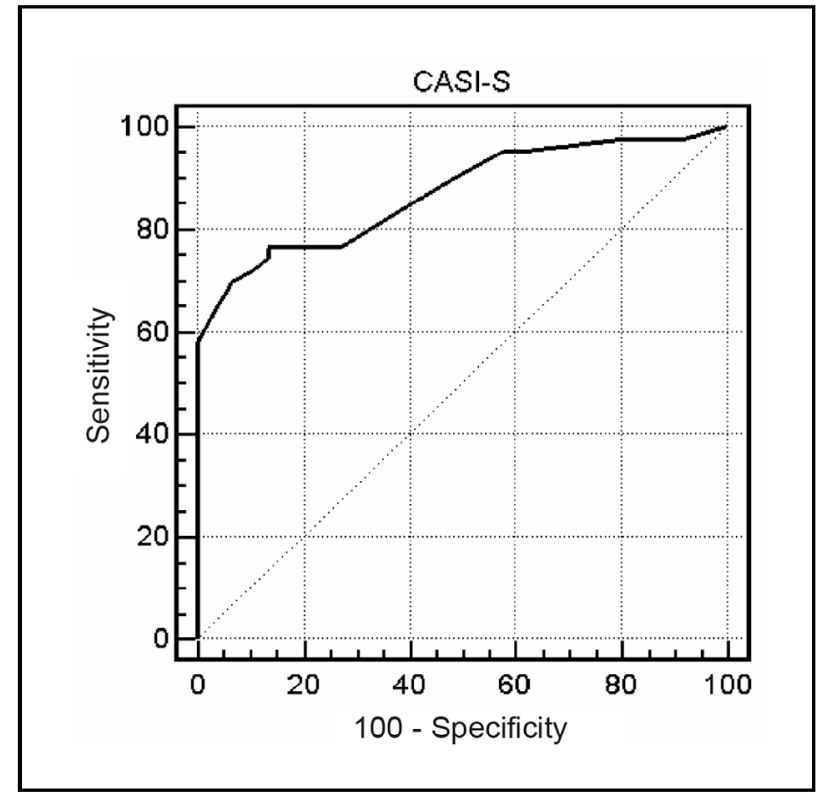

Fig 1. Receiver operating characteristic (ROC) curve for CASI-S in the prediction of dementia.

scores, patients with mild degrees of dementia had median score of 19 , and mean of 20.5 (SD $=6.7$; range: 11-33); those with moderate degrees had median of 9, and mean of 16.5 (SD = 9.3; range: $6-28$ ); and those with severe degrees, median of 1.5 , and mean of 2.4 (SD = 2.3; range: 0-8). ANOVA revealed significant differences between these three groups $[\mathrm{F}(2$, $40)=27.8439, p=0.0001]$, on account of those with severe as compared to those with mild $(p=0.0001)$ and moderate $(p=0.0005)$ dementia. The differences between those with mild and moderate dementia were not statistically significant $(p=0.2138)$.

CASI-S accuracy, given by the area under the ROC curve (Fig 1), was 0.87 (i.e., 87\%), with standard error of 0.032 , and $95 \%$ confidence intervall between 0.795 and 0.925 . Table 4 shows the sensitivity, specificity, positive likelihood ratio (LR), and negative LR for different CASI-S cut-off points. The sensitivity increased gradually from $51 \%$ to $100 \%$ when the CASI-S cut-off point went from $16 / 15$ to $33 / 32$, while the specificity showed the opposite pattern with an accelerating decrease after the cutoff 26/25. The cut-off point chosen for diagnosis of cognitive deficit was $24 / 23$ (i.e., $\leq 23$ ), with which sensititivy is $76.7 \%$, specificity $86.5 \%$, positive LR 5.68 , and negative LR 0.27 . Thirty-three demented and 10 controls scored below this point.

Cut-off point for subjects with age equal to or above 70 years (comprising 28 demented and 35 controls) was $21 / 20$ (i.e., $\leq 20$ ), with which sensitivity is $71.4 \%$, specificity $97.1 \%$, positive LR 25 , and ne- gative LR 0.29. Among these subjects, the accuracy was $89.2 \%$, with standard error 0.041 , and $95 \%$ confidence intervall between 0.789 and 0.956 .

With addition of the drawing test, CASI-S accuracy is virtually identical (sensititivy of $76.7 \%$, specificity of $86.5 \%$, positive $L R$ of 5.68 , and negative LR of 0.27 ), but among subjects aged 70 years or above, the specificity increased to $100 \%$, while the sensitivity decreased to $67.9 \%$. CASI-S subtests of registration, orientation, verbal fluency, and recall could distinguish patients from controls $(p \leq 0.0001)$, and they showed high negative correlation with the degree of cognitive deterioration.

\section{DISCUSSION}

As shown by the performance of 172 normal volunteers, CASI-S scores were highly correlated to the educacional level, but hardly to age. The slight correlation to age was explained by the higher education of the youngest age group (from 40 to 49 years), and it disappears when this group is excluded from the analysis. This secondary effect of education has been shown in other Brazilian validation studies of cognitive screening tests, as for the MMSE ${ }^{15-17}$ and Mattis Dementia Rating Scale ${ }^{18}$.

The effect of education was seen only in the recall subtest, on account of the poor performance of the illiterate as compared to the other scholing $g$ roups. The other subtests, as the shortened CASI$S$ version of verbal fluency task, were not influenced by education, in disagreement with what has been reported for the longer ( 1 minute) version of this task $^{19,20}$. It is well known that individuals with low education usually have difficulties with metacognitive tests, as with the decontextualized task of repeating and recalling three words. Formal education might influence this kind of task by training individuals in efficient learning and retrieval strategies $^{21}$. This effect tends to be slight or to disappear when the educational level of the sample is high, as shown in a Swedish population-based study of MMSE accuracy ${ }^{22}$. However, as noticed by Teng et al. ${ }^{3}$, it is unrealistic to expect that the influence of education can be fully eliminated in dementia scre ening tests.

All CASI-S subtests could discriminate very well between dementia patients and controls. Obviously, this doesnot mean that these subtests can differentiate between $A D$ and other causes of cognitive deficit. In the sample we studied, CASI-S diagnostic accuracy was good, particularly as regards its spe cificity (97.1\%) among subjects aged 70 years or 
above. However, for the chosen cut-off point (24/23), the sensitivity $(76.7 \%)$ and specificity $(86.5 \%)$ were lower than those found by Teng et al. ${ }^{23}$ in an epidemiological study of 219 subjects with dementia and 5712 normal controls. Plausible explanations for this discrepancy may be that our study is hospital-based, our sample size is smaller, and our dementia patients had slightly higher education than controls (though not statistically significant).

CASI-S accuracy was not improved by the addition of the drawing test, even though its specificity was lifted up to $100 \%$ among subjects aged 70 years or above (but with decrease of its sensitivity and increase of evaluation time). Moreover, this task was highly difficult for subjects with low education. Thus, its addition to CASI-S seems to be of no benefit.

In conclusion, CASI-S is relatively easy and quick to apply, and differently from MMSE or BOMC, it has a graded scoring of responses allowing a wider coverage of difficulty levels, being fitted for differentia ting among nondemented persons or among patients in advanced stages dementia. Although it does not require reading, writing, drawing, or arithmetic calculation, it includes metacognitive tasks, for this reason being influenced by schooling. Larger samples of patients and controls are needed to more reliably establish the tests discriminative power.

\section{REFERENCES}

1. Folstein MF, Folstein SF, McHugh PR: Mini-Mental State. A practical method for grading the cognitive state of patients for the clinician. J Psychiatric Res 1975;12:189-198.

2. Katzman R, Brown T, Fuld P, Peck A, Schechter R, Schimmel H. Validation of a short orientation-memory-concentration test of cognitive impairment. Am J Psychiatry 1983;140:734-739.

3. Teng EL, Hasegawa K, Homma A, et al. The Cognitive Abilities Screening Instrument (CASI): a practical test for cross-cultural epidemiological studies of dementia. Int Psychogeriatrics 1994;6:45-58.

4. Teng EL, Riesenberg LA, Hall NK, Brozovic B, Ivan LM. Comparisons among three screening tests for dementia. Clin Neuropsychol 1997; 11:307-308

5. Tsai RC, Lin KN, Wu KY, Liu HC. Improving the screening power of the Cognitive Abilities Screening Instrument, Chinese version. Dement Geriatr Cogn Disord 2004;18:314-320.

6. Morris JC. The Clinical Dementia Rating (CDR): current version and scoring rules. Neurology 1993;43:2412-2414.

7. Magaziner J, Basset SS, Hebel JR. Predicting performance on the MiniMental State Examination. J Amer Geriatrics Soc 1987;35:996-1000.

8. Fillenbaum GG, Heyman A, Wilkinson WE, Haynes CS. Comparison of two screening tests in Alzheimer's disease. Arch Neurol 1987;44:924-927.

9. Jacobs DM, Sano M, Dooneief G, Marder K, Bell KL, Stern Y. Neuropsychological detection and characterization of preclinical Alzheimer's disesase. Neurology 1995;45:957-962.

10. American Psychiatric Association: diagnostic and statistical manual of mental disorders 4. Washington, DC: American Psychiatric Association, 1994.

11. McKahnn G, Drachman D, Folstein M, Katzman R, Price D, Stadlan EM. Clinical diagnosis of Alzheimer's disease: report of the NINCDS-ADRDA Work Group under the auspices of Department of Health and Human Services Task Force on Alzheimer's disease. Neurology 1984; 34: 939-944.

12. Roth M, Huppert FH, Tym E, Mountjoy CQ. CAMDEX: The Cambridge Examination for Mental Disorders of the Elderly. Cambridge: Cambridge Univ Press, 1988.

13. SAS System for Windows, version 8.2. [Computer software]. (1999-2001). Cary, NC (USA): SAS Institute Inc.

14. Murphy JM, Berwick DM, Weinstein MC, Borus JF, Budman SH, Klerman GL. Performance of screening and diagnostic tests: Application of receiver operating characteristics analysis. Arch Gen Psychiatry 1987; 44:550-555.

15. Bertolucci PHF, Brucki SMD, Campacci R, Juliano Y. O Mini-Exame do Estado Mental em uma população geral: impacto da escolaridade. Arq Neuropsiquiatr 1994;52:1-7.

16. Engelhardt E, Laks J, Marinho VM, Rozenthal M, Quitério T. Triagem cognitiva em idosos normais: a importância do binômio idade/escolaridade. Arq Neuropsiquiatr 2002; 60(Suppl 1):S208.

17. Brucki SMD, Nitrini R, Caramelli P, Bertolucci PHF, Okamoto IH. Sugestões para o uso do Mini-Exame do Estado Mental no Brasil. Arq Neuropsiquiatr 2003;61:777-781.

18. Porto CS, Fichman HC, Caramelli P, Bahia VS, Nitrini R. Brazilian version of the Mattis Dementia Rating Scale: diagnosis of mild dementia in Alzheimer's disease. Arq Neuropsiquiatr 2003;61:339-345.

19. Kempler D, Teng EL, Dick M, Taussig IM, Davis DS. The effects of age, education, and ethnicity on verbal fluency. J Int Neuropsychol Soc 1998;4:531-538.

20. Caramelli P, Carthery MT, Porto CS, Fichman HC, Bahia VS, Nitrini R.Verbal fluency test in the diagnosis of mild Alzheimer's disease: cutoff scores in relation to educational level. Arq Neuropsiquiatr 2003;61 (Suppl 2):S71.

21. Folia V, Kosmidis MH. Assessment of memory skills in illiterates: strategy differences or test artifact? Clin Neuropsychol 2003;17:143-152.

22. Fratiglioni GM,Viitanen M, Winblad B. Accuracy of the Mini-Mental Status Examination as a screening test for dementia in a Swedish elderly population. Acta Neurol Scand 1993;87:312-317.

23. Teng EL, Larson EB, Lin KN, Graves AB, Liu HC. Screening for dementia: the Cognitive Abilities Screening Instrument - Short Version (CASIShort). Presentation at the Annual Convention of the American Psychological Association San Francisco, 1998. 